\title{
Angioedema in pediatric heart transplant recipients-reporting C1-esterase inhibitor deficiency without analysing protein
}

\author{
Anette Bygum • Eva R. Rasmussen \\ Received: 26 January 2014 / Accepted: 5 March 2014 / Published online: 11 April 2014 \\ (C) Springer-Verlag Berlin Heidelberg 2014
}

Sir,

We read with interest the paper by Pabst and coworkers, " $\mathrm{C} 1$ esterase inhibitor deficiency in pediatric heart transplant recipients: incidence and findings on ultrasound" [1], and would like to comment. The retrospective study described a cohort of 207 children and adolescents who had undergone heart transplantation and were treated with immune inhibitors and angiotensin converting enzyme inhibitors. In three patients, abdominal angioedema was suspected based on a sudden onset of abdominal pain, a thickened bowel wall and presence of ascites. The symptoms and signs resolved spontaneously after a mean of 3 days supporting the diagnosis of angioedema. The authors importantly emphasized awareness of this condition with associated radiologic findings to avoid unnecessary surgical exploration.

According to the title of the paper, $\mathrm{C} 1$-esterase inhibitor deficiency was found. We searched with interest for these data in the article, however despite detailed reading and personal communication with the corresponding author, we realise that $\mathrm{C} 1$-esterase inhibitor measurements were not performed. This means that the title and some of the conclusions should be changed.

C1-esterase inhibitor deficiency is a rare condition seen in patients with hereditary angioedema (prevalence around 1:70,000) or acquired angioedema with C1-esterase inhibitor deficiency reported in fewer than 200 patients worldwide [2, 3]. We are not aware of any patients with angiotensin converting enzyme-inhibitor or immune inhibitor induced acquired angioedema with $\mathrm{C} 1$-esterase inhibitor deficiency documented in the

\footnotetext{
A. Bygum $(\bowtie)$

HAE Centre Denmark, Department of Dermatology and Allergy Centre, Odense University Hospital, Sdr. Boulevard 29, 5000 Odense C, Denmark

e-mail: anette.bygum@rsyd.dk

\section{E. R. Rasmussen}

Department of Otorhinolaryngology, Head and Neck Surgery, Koege Hospital, Lykkebaekvej 1, 4600 Koege, Denmark
}

literature and neither found that such a condition was reported in this study.

In the present study, two of the three reported cases were treated with everolimus and an angiotensin converting enzyme inhibitor (lisinopril) while the third case was treated with tacrolimus but did not receive any angiotensin converting enzyme inhibitor. Both immune inhibitors alone or in combination with angiotensin converting enzyme inhibitors have earlier been reported to induce angioedema. Cases of drug-induced acquired angioedema do not have $\mathrm{C} 1$-esterase inhibitor deficiency, which is erroneously mentioned in the discussion section of the paper with a reference to Zvidi et al. [4].

In conclusion, the paper describes and illustrates very nicely three patients with probable drug-induced abdominal angioedema, which seems to be a risk in heart transplant recipients treated with everolimus, tacrolimus and/or angiotensin converting enzyme inhibitors. The mechanism of the latter condition is not $\mathrm{C} 1$-esterase inhibitor deficiency but possibly a decreased degradation of bradykinin [5].

Conflict of interest None.

\section{References}

1. Pabst S, Hamscho N, Roller F et al (2014) C1-esterase inhibitor deficiency in pediatric heart transplant recipients: incidence and findings on ultrasound. Pediatr Radiol 44:258-264

2. Bygum A (2009) Hereditary angio-oedema in Denmark: a nationwide survey. Br J Dermatol 161:1153-1158

3. Bygum A, Vestergaard H (2013) Acquired angioedema-occurrence, clinical features and associated disorders in a Danish nationwide patient cohort. Int Arch Allergy Immunol 162:149-155

4. Zvidi I, Gal E, Rachamimov R et al (2007) Tacrolimus-induced intestinal angioedema: diagnosis by capsule endoscopy. Case Rep Gastroenterol 1:1-6

5. Rasmussen ER, Mey K, Bygum A (2013) Angiotensin converting enzyme-induced angioedema-a dangerous new epidemic. Acta Derm Venereol. doi:10.2340/00015555-1760 [Epub ahead of print] 